\title{
As Travestis, Transexuais e Transgêneros (TTTs) e a escola: Entre a (re)produção e a denúncia dos corpos abjetos
}

The Travestis, Transexual and Transgender (TTTs) and School: Between the (re)production and the denounce of the abject bodies

Las Travestis, Transexuales y Transgenerales (TTTs) y Escuela: Entre la (re)producción y denuncia de los cuerpos objetos

Luís Henrique Raimundo ORCID: https://orcid.org/0000-0003-0228-4521 Universidade Federal de Pernambuco, Brasil E-mail: luiz2145.henrique@gmail.com

Marcelo Henrique Gonçalves de Miranda ORCID: https://orcid.org/0000-0001-9805-4792 Universidade Federal de Pernambuco, Brasil E-mail: marcelo.gmiranda@ufpe.br Anna Carolliny da Silva ORCID: https://orcid.org/0000-0003-3200-3137 Universidade Federal de Pernambuco, Brasil E-mail: annacarolliny0811@gmail.com

Bárbara Aparecida Rodrigues Santos Silva ORCID: https://orcid.org/0000-0003-3047-2503 Universidade Federal de Pernambuco, Brasil E-mail: barbara.aparecida@ufpe.br

Davi Silva Nascimento

ORCID: https://orcid.org/0000-0001-9283-4966 Universidade Federal de Pernambuco, Brasil E-mail: davi.silvanascimento@ufpe.br

Jéssica Cristina de França Almeida ORCID: https://orcid.org/0000-0002-4036-7777 Universidade Federal de Pernambuco, Brasil E-mail: jessicalmeida110@gmail.com

Lhays Thaynnara Silva Santos ORCID: https://orcid.org/0000-0002-1972-2092 Universidade Federal de Pernambuco, Brasil E-mail: 1haysthaynnara20@gmail.com

Petterson Santos Rocha

ORCID: https://orcid.org/0000-0002-0417-9859 Universidade Federal de Pernambuco, Brasil E-mail: pettersonrocha18@gmail.com

\section{Resumo}

Este trabalho visa conhecer a relação das TTTs (Travestis, Transexuais e Transgêneros) com o ambiente escolar e tenta identificar como esta relação contribui para a saída das TTTs das instituições de ensino. A pesquisa possui abordagem qualitativa e quantitativa, predominando o caráter qualitativo, e segue a linha de dois tipos de tipologias, descritiva e explicativa. Desse modo, um questionário foi utilizado como instrumento de coleta de dados, divulgado via mídias sociais, buscando identificar vivências escolares dessa comunidade. Como resultado, obtivemos a contribuição de oito participantes, possibilitando a seleção de discursos relevantes para a discussão do estudo. Concluímos que o cotidiano escolar deles (as), que deveria ser um ambiente de inclusão e acolhimento, por muitas vezes tornou-se hostil, contribuindo para a evasão escolar, sendo, portanto, urgente que essa temática esteja constantemente presente em discussões acadêmicas, atravessando os cursos de licenciaturas em direção à Educação Básica, na tentativa de transformar a triste realidade que nos rodeia, enquanto sociedade e humanos.

Palavras-chave: Transfobia; Vivências na escola; Evasão escolar.

\section{Abstract}

This work aims to know the relationship between TTTs (Travestis, Transsexual and Transgenders) and the school environment, and tries to identify how this relationship contributes to the exit of TTTs from educational institutions. The research has a qualitative and quantitative approach, predominating the qualitative, following two types of 
typologies, descriptive and explanatory. Thus, a questionnaire was used as an instrument to collecting data, disseminated through social media, seeking to identify school experiences of this community. As results, we obtained the contribution of eight participants, enabling the selection of relevant speeches for the discussion of this study. We concluded their school daily life, which should be an environment of inclusion and acceptance, has often become hostile, contributing to school evasion, and therefore it is urgent this topic to be constantly present in academic discussions, going through the licentiate courses toward Basic Education, in an attempt to transform the sad reality that surrounds us, as a society and as humans.

Keywords: Transphobia; Experiences at school; School dropout.

\section{Resumen}

Este trabajo tiene como objetivo conocer la relación de los TTT (Travestis, Transexuales y Transgéneros) con el entorno escolar e intenta identificar cómo esta relación contribuye a la salida de los TTT de las instituciones educativas. La investigación tiene un enfoque cualitativo y cuantitativo, predominando el carácter cualitativo, y sigue la línea de dos tipos de tipologías, descriptiva y explicativa. Así, se utilizó un cuestionario como instrumento de recogida de datos, difundido a través de las redes sociales, buscando identificar las experiencias escolares de esta comunidad. Como resultado, obtuvimos la contribución de ocho participantes, lo que permitió la selección de discursos relevantes para la discusión del estudio. Concluimos que su vida escolar cotidiana, que debería ser un ambiente inclusivo y acogedor, se ha convertido muchas veces en hostil, contribuyendo a la deserción escolar, y por lo tanto, es urgente que este tema esté constantemente presente en las discusiones académicas, atravesando los cursos de formación docente hacia la Educación Básica, en un intento de transformar la triste realidad que nos rodea como sociedad y seres humanos.

Palabras clave: Transfobia; Experiencias en la escuela; Abandono escolar.

\section{Introdução}

O Brasil é um país constantemente marcado por preconceitos, discriminações, exclusões e violências (simbólica, física, sexual etc.) contra pessoas consideradas diferentes, seja por questões étnicas, raciais, sexuais e de gênero. Segundo Peres (2009), isso ocorre porque ainda somos intensamente influenciados por um processo de inteligibilidade heteronormativo ou da heterossexualidade compulsória ${ }^{1}$, lgbtfobia, racista. Isto é, há uma interpelação do indivíduo como corpos abjetos, excluídos e subjugados na (re)produção da hegemonia dos pares dicotômicos excludentes e hierarquizados (Butler, 2003, 2017).

Nesse sentido, Francisco, Mendes e Meira (2019) nos apontam que os conceitos que compreendem gênero, sexualidade e diversidade na escola, infelizmente, ainda parecem distante da realidade, desencadeando, portanto, um ambiente de exclusão nas instituições em decorrência da invisibilidade da temática por parte de educadores e educadoras, tendo como consequência a perpetuação de violências e preconceitos. Desse ponto, percebemos o quanto se faz necessário que a temática da diversidade de gênero se torne mais presente em estudos voltados para instituições desde o ensino básico, aproximando os conceitos da percepção de toda a comunidade escolar na tentativa de se tornarem mais conscientes quanto ao assunto em questão.

Para Saffioti (1997, p. 59), “a subjetividade é construída por meio das relações sociais. Sujeito e objeto experimentam dois momentos: o da fusão e o da autonomia. O sujeito é constituído em gênero, classe e raça/etnia: é, portanto, múltiplo”. No caso das pessoas travestis, transexuais e transgêneros (TTTs) esse processo de subjetivação também acontece pelo corpo. Há sempre um processo de assujeitamento do sujeito nas categorizações corpo (macho-fêmea), gênero (homem-mulher) e sexualidade (heterossexual-homossexual) (Bento \& Pelucio, 2012; Miranda \& Oliveira, 2012; Bento, 2017) que reverbera em estigmatizações e abjeções.

Nesse caminho, Peres (2009, p. 238) afirma que:

\footnotetext{
${ }^{1}$ Heterossexualidade compulsória diz respeito à concepção social que vê a heterossexualidade como uma ordem: "todos deverão ter claro o que é ser homem e ser mulher, todos deverão ser heterossexuais, constituir família, ter filhos, netos... E se por esta razão estiver para morrer de tédio ou angústia, a ordem é a de buscar as razões disso naqueles que descumprem as normas” (Peres, 2009, p. 259).
} 
Nos processos de estigmatização, é paulatinamente estabelecido todo um sistema de depreciação e desvalorização que leva a pessoa a se inferiorizar, perder a autoestima e aceitar toda a imposição dos estigmas, em decorrência da introjeção de valores como verdades absolutas e de modos de ver que justificariam a sua desqualificação e exclusão como algo natural, justo e inevitável.

Esses processos de estigmatização começam cedo, pois, as resistências ao biopoder ${ }^{2}$ são expressas desde a infância às TTTs mesmo que de forma ingênua e inocente, por seu modo de vestir e seus adereços (Peres \& Toledo, 2011). Assim, em muitos casos, há a exclusão familiar, da vizinhança e também pela escola:

A partir da exclusão familiar e da vizinhança, as relações estabelecidas entre travestis, transexuais e transgêneros e a escola também se mostram bastante prejudicadas. A escola apresenta muita dificuldade no trato da orientação sexual e de identidade de gênero, mostrando-se muitas vezes insegura e perdida diante das cenas que não estão presentes em seus manuais. Neste sentido, reifica os modelos sociais de exclusão por meio de ações de violência (discriminação e expulsão) ou de descaso, fazendo de conta que nada está acontecendo (não escuta as denúncias da dor da discriminação). (Peres, 2009, p. 245)

Nesse contexto, este estudo tem como objetivo: compreender os principais fatores que influenciam a evasão/expulsão escolar das travestis, transexuais e transgêneros (TTTs) a partir de suas percepções.

Vale ressaltar que a escola desempenha papel fundamental na construção da cidadania, pois, tem o dever do pleno desenvolvimento dos indivíduos, tornando-os críticos, solidários, participativos e, consequentemente, capazes de transformar a realidade que os cerca (Freire, 2011). Este estudo busca oferecer reflexões e incentivos para a superação dos preconceitos e a garantia dos direitos das TTTs, categorizadas como corpos abjetos, isto é, não humanos em nossa sociedade

Mesmo diante desse quadro de exclusão e violência, segundo Bento (2017), nos últimos anos, houve um crescente número de pesquisas que discutem os múltiplos significados de gêneros e suas respectivas interseccionalidades. Juntamente a isso, a presença das pessoas trans (travestis, transexuais, transgêneros, cross dress, drag kings, drag queens) têm se mostrado, felizmente, mais frequente na vida acadêmica, seja na presença de estudantes ou docentes. Essas observações nos indicam certa transformação no respeito à diversidade. Todavia, ainda não é suficiente, pois, mais estudos, políticas e processos pedagógicos se fazem necessários para que a visibilidade da temática se torne presente, contribuindo para a ruptura de discriminações e preconceitos ao mesmo tempo em que fortaleça o caráter plural e democrático da sociedade e da escola.

\section{Das categorias dicotômicas à paródia corporal como desestabilizações da inteligibilidade heteronormativa}

O nome atribuído às pessoas e as coisas é uma forma de classificação social. Essa classificação materializa categorias de corpo, gênero e sexualidade. Assim, ao terem o direito de escolher o nome social, as travestis e pessoas trans garantem um mínimo de dignidade em sua existência em harmonia com sua identidade de gênero.

Para Arán, "o/a transexual passa a trajar-se tal como se percebe subjetivamente, indo na contramão de sua identidade civil, o que em muitos casos gera constrangimento social, pois o nome não condiz com o que se mostra socialmente" (2006, p. 130).

No entanto, o reconhecimento das pessoas trans e travestis, respeitando a maneira pela qual se mostram e se identificam socialmente, não coincide com a realidade. A sociedade insiste em categorizar as TTTs via uma suposta essencialização naturalizada, biológica, e não como essas pessoas se reconhecem. A Organização Mundial de Saúde (OMS) e as organizações de ativistas transexuais e travestis:

\footnotetext{
${ }^{2}$ Conceito utilizado por Foucault (2007), na História da Sexualidade I. Para Peres e Toledo, fazendo referência a Foucault “(...) o biopoder é aquele que será responsável pela disciplinarização dos corpos e pela regulação dos prazeres, de modo que todos se voltem para a heterossexualidade e correspondam aos padrões de gênero e de desejo socialmente determinados para seu sexo biológico" (2011, p. 264).
} 
São unânimes em afirmar que o nome civil, aquele registrado nos documentos legais, muitas vezes é usado para causar constrangimento em determinados espaços públicos. Essa tem sido considerada a principal causa da evasão escolar e do afastamento dessa população dos serviços públicos (Biancarelli, 2010, pp. 131-132).

O processo para alterar o nome civil é muito demorado e isso atrapalha a vida e bem-estar dessas pessoas. Este fato contribui para a abjeção, pois, antes mesmo de buscarem a alteração do nome, elas já passaram pela mudança física. Entretanto, mesmo que nome social, via leis, seja utilizado nas escolas públicas brasileiras em treze estados, documentos como o histórico escolar, e demais documentos externos, adotam exclusivamente o nome civil ocasionando constrangimentos e reforçando a transfobia ${ }^{3}$.

Para serem sujeitos plenos de direitos, transexuais e travestis reivindicam que o nome acompanhe as mudanças físicas, uma vez que ter um corpo feminino com nome masculino ou vice-versa nos documentos oficiais produz grandes transtornos em suas vidas. Tal direito ao nome social nos documentos oficiais garante que os direitos humanos como direitos básicos não sejam violados:

Pensar em direitos humanos é pensar na constituição de preceitos e concepções que nos permitam compreender que, independentemente de origem, credo, cor da pele, orientação sexual, faixa etária e classe social, todos os sujeitos respeitadas as diferenças culturais, sociais, históricas etc. - numa sociedade como a nossa são passíveis de direitos e deveres (Santos \& Araújo, 2009, p. 22).

Nesse contexto de exclusão e transfobia, a escola não promove o respeito e aprendizado com a diversidade/diferença. Tal processo de transfobia é constatado pelo número tão reduzido de travestis e pessoas trans nas escolas e universidades. Assim, a instituição educacional termina (re)produzindo as desigualdades sociais e a exclusão dos corpos socialmente categorizados como objetos.

Indo de encontro a essa transfobia, a "lei do nome social coloca em xeque a reivindicação pela quebra nas normas de gênero e das identidades fixas" (Lessa \& Oliveira, 2013, p. 139). Essa lei pode minimizar essa violência sofrida pelas travestis, transexuais e transgêneros nas instituições educacionais e contribuir para que existam mais reconhecimento, inclusão e respeito com a diversidade.

A divisão binária com base nos pares dicotômicos excludentes e hierarquizados de corpo, gênero e sexualidade é um processo de inteligibilidade construído historicamente que pode ser desestabilizado e desconstruído (Butler, 2003; Arán, 2006; Silva et al., 2020).

O corpo, segundo Benedetti (1997), é um passe para a inserção do indivíduo no meio social que ganha sentidos socialmente atribuídos em um processo de inteligibilidade. A travesti constrói a sua identidade mediante a negação de uma suposta naturalização biologizante deste corpo que é pré-determinado discursivamente e que foi esquecido os sentidos condensados sobre essa materialidade, ganhando status pré-discursivo. O corpo assume, então, uma função de suporte enquanto categorização da pessoa no âmbito social. Entretanto, esse suporte é negado às travestis e às pessoas trans classificando como corpo abjeto (Butler, 2003).

O corpo é uma categoria simbolicamente constituída em um processo de inteligibilidade heteronormativo materializando significados, expressando sentimentos, ideias etc. O corpo é mais do que um espaço físico da matéria. Ele é um

\footnotetext{
${ }^{3}$ Segundo Podestá, transfobia “(...) é um conceito (...) para designar e analisar as múltiplas violências contra pessoas trans - pessoas que vivem a transgeneridade. (...) O termo pode ser evocado para representar um grupo heterogêneo de violências específicas que atingem mulheres transexuais, travestis, homens trans, pessoas não binárias, entre outras. Conceitualmente, a transfobia (...) tem uma relação com a abjeção e a estigmatização desdobradas do fenômeno da transgeneridade, no contexto de uma norma de gênero dependente da cisgeneridade" (Podestá, 2019, p. 363).
} 
forte meio de expressão, de identidade, que pode sim ser reconstruído com a finalidade de se adequar a uma identidade de gênero e de sexualidade (Jayme, 2002).

A paródia corporal, materializada pelas travestis e pelas pessoas trans, deixa evidente a ficcionalidade das categorias heteronormativas na sociedade contemporânea. Nessa perspectiva, há possibilidade de subverter a opressão engendrada pelos pares categoriais da inteligibilidade heteronormativa (Butler, 2003).

A paródia (ou a paródia corporal para Butler) tem uma característica ambivalente, porque se repete ao mesmo tempo em que se diferencia do objeto inspirador. Essa ambivalência é estabelecida:

Entre a repetição conservadora e a diferença revolucionária, faz parte da própria essência paradoxal da paródia: assim, não é de surpreender que os críticos não se encontrem de acordo relativamente à intenção da paródia (...) existem muitas formas possíveis de ethos da paródia: pretender-se inocentemente reverente: ridicularizadora? Didática? Mnemônica? Irônica? Aceita ou resiste ao outro? (Hutcheon, 1985, p. 99).

As travestis, sendo esses corpos paródicos que subvertem a ficcionalidade da lógica linear do corpo/sexo-gênerosexualidade, exploram variados tipos de identidade de gênero, desestabilizando a inteligibilidade heteronormativa dos pares dicotômicos categoriais, excludentes e hierarquizados: corpo (macho-fêmea) gênero (homem-mulher), sexualidade (heterossexual-homossexual). Mesmo se apresentando alinhadas ao sexo biológico, elas conseguem extrair várias possibilidades atreladas ao que cada identidade de gênero proporciona (Kulick, 2008).

Contudo, as travestis (e as pessoas trans), exatamente por deixarem mais evidente essa ficcionalidade sobre o corpo, gênero e sexualidade, sofrem sanções bem mais violentas do que algumas lésbicas e alguns gays. As travestis são frequentemente associadas a atos de violência, prostituição, promiscuidade, além de várias IST (Infecções Sexualmente Transmissíveis) e HIV/AIDS (Síndrome da Imunodeficiência Adquirida) (Chidiac \& Oltramari, 2004).

As discriminações voltadas para a expressão de gênero surgem a partir dos processos que inscrevem gêneros a um corpo sexuado, nesse sentido, Bento (2017, p. 83) aponta que podemos analisar gênero como uma sofisticada tecnologia social heteronormativa, operacionalizada pelas instituições médicas, linguísticas, domésticas, escolares e que produzem constantemente corpos-homens e corpos-mulheres.

Dessa maneira, as TTTs ao assumirem a posição de gênero ao qual se identificam, carregam em seu corpo uma história marcada por conflitos quanto às normas de corpo, gêneros e de sexualidade em que a sociedade as categoriza como "doente", "anormais" e "pecaminosas" exacerbando a superioridade da inteligibilidade estrutural da heteronormatividade (Butler, 2003; Bento, 2008).

Para Bento (2008, p. 163), "colocar como doença a transexualidade talvez seja a mais cruel, pois irradia a convicção de que são pessoas inferiores”. Esse pensamento evidencia como a sociedade marginaliza as pessoas TTTs, não apenas silenciando diante dos crimes cometidos contra elas, mas também, classificando essa transfobia como algo normal ou às tratando doentes, perturbadas que merecem morrer, pois são corpos abjetos, isto é, não humanos.

Quando é posta em questão a humanidade, as TTTs podem não se sentirem próprias, não se sentirem dignas ou capazes de se defender de forma alguma. Essa humanidade é questionada a tudo que foge do binário de corpo, gênero e sexualidade. Nesse caminho, as TTTs, desde sua infância ao se perceber diferente, diante da inteligibilidade heteronormativa, não se veem como detentora de seus direitos. Por isso, "o afastamento do que se é chamado de humanidade reduz a capacidade de o sujeito entrar na esfera dos direitos e reivindicá-los” (Bento, 2008, p. 164).

Para Bento (2017), o assujeitamento do sujeito pode ser "um momento de atribuição de sentido para as várias surras, insultos e rejeições familiares". Ter um/a pênis/vagina e não conseguir agir de acordo com as expectativas é uma descoberta vivenciada com grande surpresa para alguns" (2017, pp. 179-180). 
A partir das descobertas corporais, dos sentimentos e dos desejos, as TTTs se percebem em um corpo-sexuado obrigados/as a relacionar-se com partes do corpo que não dizem respeito com o gênero ao qual se identificam. São nesses momentos que muitos relatam o sentimento de perda de sonhos, liberdade, perspectivas futuras, desencadeando certa busca pela construção de suas próprias identidades (Bento, 2017).

Nesse contexto, a escola pode ser um espaço de reprodução da categorização dos corpos como objetos. A escola é um ambiente onde, infelizmente, supõe comportamentos "naturais" voltados para determinados corpos-sexuados, como, por exemplo, o controle no que diz respeito ao tipo de roupa a usar, aos comportamentos heteronormativos e ou da heterossexualidade compulsória.

Lamentavelmente, a instituição escolar também pode se tornar um lugar hostil, tanto para o sucesso acadêmico como para a saúde mental, a partir do momento que, em vez de promover políticas e práticas de combate à discriminação, reforçam a rejeição e padrões de policiamento de gênero que resultam em violência, não apenas física, mas também simbólica. Bento (2008) afirma que na escola:

$\mathrm{Na}$ verdade, há um desejo em eliminar e excluir aqueles que contaminam o espaço escolar. Há um processo de expulsão e não de evasão. É importante diferenciar "evasão" de "expulsão", pois, ao apontar com maior precisão as causas que levam crianças a não frequentarem o espaço escolar, teremos como enfrentar com eficácia os dilemas que constituem o cotidiano escolar, entre eles, a intolerância alimentada pela homofobia (2008, p. 166).

A Autora ainda salienta que não há realmente evasão escolar. Tudo se dá via um processo minucioso, de "desinfetar" o ambiente escolar. Começa com uma "simples brincadeira" pejorativa que vai se agravando chegando a agressões físicas. Estas, geralmente, são vistas pelos funcionários da escola apenas como uma brincadeira de crianças, em que os autores de tais atos fingem que brincam e os demais (TTTs) fingem que não está acontecendo nada.

Depois da família, a escola é o primeiro grupo social que uma criança tem contato e, os fatores que levam a mesma a abandonar seus estudos em hipótese alguma devem ser considerados normais. A problematização em sala dessa transfobia é tão necessária como os demais componentes curriculares. Bento (2008) afirma que o fato do aluno interromper os estudos parece algo inevitável, natural, sugerido, portanto, que essa discussão não diz respeito ao ambiente escolar e que a instituição nada pode fazer" (2008, p. 171). Ou seja, parece "comum", um (a) aluno(a) TTT desistir dos estudos no atual contexto escolar, tornando-se característica da escola, demonstrando o quão difícil é o real quadro brasileiro com relação a esse grupo que é constantemente discriminado e colocado à margem da sociedade.

Bento (2017) destaca que "a escola é lembrada como um espaço de terror, onde os/as transexuais eram vítimas de todo tipo de preconceito" (2017, p. 205). A autora expõe que pode se constatar o baixo nível de escolaridade da população TTT, pois, a escola é um lugar de produção e reprodução de transfobia (homofobia e lesbofobia).

Infelizmente, são esses exemplos de exclusão que toda a comunidade LGBTQIA (Lésbicas, Gays, Bissexuais, Transexuais, Queer, Intersexo e Assexual) sente na escola. Nesse grupo, as TTTs, são um dos principais alvo de violência como resultado de uma estrutura heteronormativa de inteligibilidade.

Porém, a instituição educacional também materializa um lugar de luta, de resistência e de promoção da cidadania, respeito e aprendizado com a diferença, subvertendo essa ordem hegemônica, excludentes e opressora. Um ambiente escolar que reconheça e inclua pode ser o único lugar de refúgio para as TTTs, visto que, assim como todo estudante, essas pessoas trans carregam consigo a necessidade de se sentirem acolhidas e reconhecidas em sua legitimidade. 


\section{Metodologia}

A partir do nosso objetivo da pesquisa: compreender os principais fatores que influenciam a evasão/expulsão escolar das travestis, transexuais e transgêneros (TTTs) a partir de suas percepções. A pesquisa é de natureza qualitativa, uma vez que busca ter acesso ao mundo subjetivo dos sujeitos da pesquisa e como esses verbalizam a transfobia sofrida por essa população em suas trajetórias escolares. Ou seja, focamos na compreensão dos aspectos da vida social das TTTs e suas relações com os ambientes escolares.

A abordagem qualitativa é caracterizada por priorizar os materiais que possam ser utilizados como fonte de informação e compreensão na sua busca por um conhecimento mais aprofundado, no caso em questão, sobre os fatores que influenciaram a expulsão das TTTs do ambiente escolar (Alves-mazotti, 1999; De Oliveira, 2007; Lüdke \& André, 1986). Assim, selecionamos como participantes de nosso estudo, as TTTs que residem em Caruaru e ou nas cidades circunvizinhas, todas localizadas no agreste de Pernambuco. Utilizamos um questionário como instrumento de coleta de dados com perguntas abertas e fechadas.

Nosso estudo é descritivo e explicativo. A descrição apresenta as características das TTTs visando expor suas principais características (Vieira, 2002). A característica explicativa busca compreender os motivos que desencadearam a evasão/expulsão do ambiente escolar vivenciada pelas TTTs (Cardoso, 2005). Sendo assim, nesta pesquisa haverá descrições acerca das TTTs e em seguida possíveis compreensões sobre as afirmações apresentadas de acordo com os dados coletados pelos questionários.

Os resultados obtidos nos questionários foram examinados através da Análise de Conteúdo que pretende utilizar o registro em si (Bardin, 1997; Fonseca Júnior \& Wilson, 2005; Bauer, 2010; Gomes, 2016). Esta metodologia de análise possibilitou categorizações visando a compreensão do universo da nossa pesquisa, tornando possível a identificação das violências vivenciadas pela população TTTs que resultaram na evasão/expulsão das instituições de ensino materializando a transfobia.

\section{Resultados e Discussão}

Nesta seção, apresentaremos as análises sobre os dados coletados por meio do questionário. O questionário utilizado foi construído com a finalidade de obter dados suficientes para alcançar o objetivo da pesquisa. Nesse sentido, partindo dos textos usados na fundamentação teórica, foram criadas, além das perguntas de identificação das pessoas, questões fechadas e abertas visando contemplar a realidade individual de cada sujeito da pesquisa e suas vivências escolares, o qual adotamos como título "A realidade da vivência escolar das TTTs (Travestis, Transgênero e Transexuais) e as principais motivações da evasão escolar".

As perguntas foram colocadas na plataforma Google Forms. Este recurso contribuiu para veiculação do referido questionário e coletar os dados, uma vez que esta é uma plataforma que possibilita a divulgação de formulários através de links compartilháveis. A partir dessa plataforma, divulgamos e compartilhamos o acesso ao questionário via mídias sociais, tais como Whatsapp, Instagram, Twitter, e, também, foi publicado perfil do Instagram do coletivo LGBTQIA+: Cores Capibaribe, @ corescapibaribe - buscando alcançar o público da pesquisa e, consequentemente, dados suficientes para análises e discussões.

Os questionários ficaram disponíveis durante três semanas, gerando um total de oito participantes da pesquisa. Sobre as questões fechadas, explicitamos os dados percentuais estatísticos abaixo. E as questões abertas, selecionamos alguns trechos mais relevantes que possibilitaram categorizações via Análise de Conteúdo (AC).

Ressaltamos que a identidade de todos os participantes da pesquisa foi mantida em sigilo, dessa maneira, identificamos os participantes da pesquisa do seguinte modo: Entrevistada 1 (E1), Entrevistada 2 (E2), Entrevistado 3 (E3), Entrevistada 4 (E4), Entrevistado 5 (E5), Entrevistado 6 (E6), Entrevistada 7 (E7) e Entrevistada 8 (E8). 
Sobre as perguntas de identificação, obtivemos as seguintes respostas dos participantes nas questões: Identificação (nome, idade), 66,67\% não informou a idade; 11,11\% revelou ter 18 anos, $11,11 \%$ tinha 21 anos e 11,11\% tinha 42 anos.

Sobre o nível de educação, as respostas ficam: 50\% dos participantes afirmaram ter ensino médio completo (dado que nos debruçamos mais adiante). Ou seja, os nossos participantes da pesquisa concluíram o ensino médio mesmo diante da violência relacionada às pessoas TTTs.

37,5\% dos participantes afirmaram que estão cursando o ensino superior, graduação. E 12,5\% responderam que possuem o ensino fundamental completo. Nesse caminho, sobre o nível de escolaridade, os sujeitos da pesquisa estão localizados entre o ensino médio e a graduação.

Já a questão sobre ocupação (cargo, ocupação laboral): 25\% informou ser recepcionista, 25\% estavam desempregadas; $25 \%$ eram estudantes; $12,50 \%$ doméstica e $12,50 \%$ era costureiro.

Sobre como os participantes da pesquisa se identificavam: Seis deles responderam que se identificam como transexuais, entres estes sendo cinco mulheres transexuais e um homem transexual, e dois homens transgêneros. Todos participantes do estudo eram transexuais ou transgêneros, mas ainda continuaremos considerando o termo TTT em alguns momentos da discussão para demarcar esse campo de produção do conhecimento.

Em seguida, foi perguntado aos participantes em que período de vida começaram a se expressarem como transexual ou transgênero. $75 \%$ afirmaram que começaram a se expressar diferente da cisgeneridade ainda na adolescência. 12,5\%, já na infância e $12,5 \%$ só na vida adulta.

Nesse aspecto, a maior parte começou a se expressar saindo da cisgeneridade para a trans durante a adolescência ou infância. Isto é, os participantes da pesquisa começaram a exceder a estrutura de inteligibilidade heteronormativa da lógica linear sexo-gênero-sexualidade enquanto ainda estavam na escola. Essa constatação só vem a reforçar a necessidade da escola ser um ambiente de reconhecimento e de inclusão para as TTTs.

Como anteriormente explicitado no artigo, inexiste apoio, acolhimento e reconhecimento por parte da família. Essa rejeição é reforçada no ambiente escolar. Nesse aspecto, os gêneros participantes da pesquisa respondem que: 62,5\% responderam que mantêm relações afetivas com suas famílias; e 37,5\% responderam que não possuem qualquer vínculo familiar. Podemos intuir que o percentual maior concentrado nos vínculos familiares nos indica algumas desestabilizações das categorias excludentes, dicotômicas e hierarquizadas de corpo/sexo, gênero e sexualidade. Ou seja, as sanções sobre os corpos objetos não são tão homogêneas em nossa sociedade. Mesmo que esse "manter" signifique algumas restrições em respeitar, aceitar e acolher uma pessoa TTT, pois, na sociedade, ainda há uma estrutura de inteligibilidade (cis)heteronormativa (Butler, 2003).

Ao se focar na escola como lugar privilegiado para desconstruir e/ou desestabilizar as categorizações dicotômicas excludentes e hierarquizadas, existe a possibilidade da promoção da cidadania e do respeito à diferença via equidade de gênero e ou da diversidade nos componentes curriculares. Essa inclusão torna possível que o ambiente escolar seja um espaço onde as pessoas poderiam usar roupas e acessórios em harmonia com as suas identidades de gênero. As respostas ficaram assim: $75 \%$ responderam que as referidas temáticas foram alguma vez abordadas na escola. E 62,5 \% explicitaram que não havia proibição no uso de roupas e acessórios de acordo com sua identidade de gênero que rompia a hegemonia cisheteronormativa.

Do total dos sujeitos da pesquisa, $25 \%$ responderam que a escola nunca trabalhou na promoção do respeito às temáticas de gênero e da diversidade sexual. E 37,5\% afirmaram que nunca puderam usar roupas e acessórios que excedessem a norma estabelecida para a lógica linear corpo-gênero-sexualidade.

Mesmo diante da alegação das TTTs (participantes da pesquisa) sobre as temáticas de gênero e diversidade sexual nas escolas, houve contradições a partir de outras respostas. Essas respostas indicam que o ambiente escolar ainda é repressor e (re)produtor da inteligibilidade (cis)heteronormativa, pois, o uso de roupas ou acessórios, de acordo com a expressão de 
gênero, eram proibidas em suas respectivas escolas. Assim, como explicitado anteriormente, a escola no lugar de acolher, reprime, discrimina e exclui as TTTs, tornando-se um lugar tóxico em que há a fortalecimento dos pares dicotômicos excludentes e hierarquizadas de corpo/sexo, gênero e sexualidade.

Gênero e sexualidade ainda é um assunto muito pouco trabalhado no ambiente escolar. A escola que deveria ser um lugar para dar acolhimento e reconhecimento da diversidade e da democracia, termina reprimindo e colaborando com o preconceito social contra as TTTs.

Esse descaso das escolas, seja por não saber lidar com o diferente ou simplesmente por discriminação, acarretando na exclusão social dessas pessoas, produzem ainda mais sofrimento para as TTTs, uma vez que elas já chegam à escola com traumas vivenciado no ambiente familiar ou comunidade onde vivem como materialização da transfobia.

Essa exclusão e violência é materializada pelo uso do banheiro em ambientes públicos. 50\% responderam sempre que podem usar o banheiro que se sentissem à vontade. Porém, as outras TTTs afirmaram da seguinte maneira: $25 \%$ responderam o uso do banheiro escolar lhes foi negado em relação com a sua identidade de gênero; $12,5 \%$ responderam que o uso do banheiro foi negado em espaços públicos; e 12,5\% responderam que foi negado o uso em espaços públicos e na escola. Ou seja, a estigmatização, discriminação e exclusão que as TTTs sofrem no ambiente escolar prejudica a socialização dessas pessoas que passam a ter uma esfera social bastante restrita, pois, elas não possuem nem o direito de utilizar o banheiro o qual se sentem mais à vontade em harmonia com sua identidade de corpo, gênero e sexualidade, conforme já apontado no estudo de Miranda e Oliveira (2016).

A seguir foi perguntado se os (as) entrevistados/entrevistadas já se reconheciam como transexual ou transgênero no ambiente escolar. Também foi solicitado aos (às) mesmos (as) que descrevessem suas vivências no ambiente escolar em decorrência das suas identidades de gênero e de que forma houve contribuições da escola no seu modo de viver na atualidade; se houve o acolhimento ou a ausência deste contribuiu para a permanência evasão/expulsão da escola. As respostas foram as seguintes:

Entre meus colegas de classe sempre existiu respeito, já alguns professores insistiam em ser transfóbicos o tempo todo (E1 Transexual Feminina, 19 anos).

Me chamo E2 Transexual Feminina, sou a primeira transexual de Santa Cruz do Capibaribe a retificar o nome e a fazer a cirurgia. Foi muito difícil! Eu tenho a minha liberdade, mas quando vim morar em Santa Cruz ganhei meu primeiro emprego. Mas infelizmente não foi tão bom assim. Foram os piores momentos da minha vida, pois passava pela discriminação e preconceito todos os dias na fábrica onde eu trabalhava. Acionei o conselho, o CRAS o CREAS e até o sindicato, mas nada foi resolvido. Hoje costuro em minha casa e, atualmente, parei e coloquei meu nome à disposição como candidata a vereadora no município (E2 Transexual Feminina, sem identificação de idade).

Ainda não (E3 Transexual Masculino, sem identificação de idade).

Não (E4 Transexual Feminina, sem identificação de idade).

Tranquilo em relação aos amigos. Mas já sofri transfobia vinda de uma professora dizendo que eu não podia usar roupas ditas masculinas se eu era uma mulher (E5 Transgênero Masculino, 20 anos).

Estudei os últimos 4 anos em uma escola bem burguesa de Recife (particular). E como burguesia padrão, bem conservadora e opressora, não havia direito de uso de banheiro nem o uso de nome social. Apenas um professor me tratava adequadamente e me respeitada como homem trans. Aconteceu casos de transfobia na sala de aula direcionada a mim. Apesar do longo processo doloroso vivido na época da escola, eu estou me profissionalizando para seguir o rumo de professor acadêmico e para além disso, hoje, participo de extensão e Pibic (Projetos de Iniciação Científica) que estudam/buscam/analisam como o gênero é tratado nas escolas, já que a temática já está incluída nos temas transversais da grade curricular escolar (E6 Transgênero Masculino, 21 anos). 
Tive acesso ao termo depois que terminei o ensino médio, mas sempre senti um incômodo em relação ao ambiente em minha volta e preferia ir ao banheiro (masculino) quando não tinha ninguém (E7 Transexual Feminina, sem identificação de idade).

Infelizmente muitos professores faziam questão de falar alto meu antigo nome, como se quisesse chamar atenção e humilhar. Alguns alunos riam, mas eu já me vestia como mulher, já me hormônizava (E8 Transexual Feminina, 42 anos).

Os relatos dos (as) entrevistados (as) nos mostraram o quão cristalizada está a escola em relação à questão dos gêneros. A escola também é o reflexo da sociedade que marginaliza as pessoas trans que fogem ao padrão heteronormativo imposto por ela. Para Bento (2008), na verdade não há evasão, mas sim uma "desinfecção" do ambiente escolar em que expulsam as pessoas trans.

Na verdade, há um desejo de eliminar e excluir aqueles que contaminam o espaço escolar. Há um processo de expulsão e não de evasão. É importante diferenciar "evasão" de "expulsão", pois, ao apontar com maior precisão as causas que levam crianças a não frequentarem o espaço escolar, teremos como enfrentar com eficácia os dilemas que constituem o cotidiano escolar, entre eles a intolerância alimentada pela homofobia [transfobia, lesbofobia] (Bento, 2008, p. 166).

Relacionando a discussão acima sobre o espaço escolar e as vivências das TTTs, perguntamos se alguma das TTTs tinham sentido a escola ultrapassar essa inteligibilidade cisheteronormativa e proporcionar certa flexibilidade e respeito às diversidades/diferenças. Ou ainda, caso não tivesse acontecido esse respeito à diversidade/diferença, como esse respeito poderia acontecer para que pessoas da comunidade travesti e trans se sentissem mais acolhidas, incluídas e reconhecidas. Obtivemos as seguintes respostas:

Não [houve acolhimento e respeito à diversidade/diferença]. Levando informações aos estudantes e aos funcionários [para promover esse respeito] (E1 Transexual Feminina, 19 anos).

A política é o melhor caminho para fazer projetos de leis de impacto social, construindo política pública para as pessoas LGBT (E2 Transexual Feminina, sem identificação de idade).

Sim (E3 Transexual Masculino, sem identificação de idade).

Não. Deve haver sempre a opção de nome social. O banheiro tem que ter placas de incentivos que são para todos. Transfobia deve se tratar como crime. Deve haver punição (E4 Transexual Feminina, sem identificação de idade).

Sim (E5 Transgênero Masculino, 20 anos).

NÃO. Não existe aula de sociologia? Vamos falar também sobre a sociedade contemporânea, a diversidade. Num existe a aula de português e por que não estudamos o processo histórico para língua neutra ser usada para pessoas não binárias? Não existe história e história do Brasil? Vamos mostrar história do movimento feminista, história do movimento LGBTQIA+. Todo o processo de luta e conquistas de direitos, quebra de hegemonias. Não dá só para falar da ditadura militar (1964), sem mostrar as minorias em luta contra o sistema opressor vigente no Brasil na época. Temas transversais são necessários e são simples de serem adicionados nas disciplinas obrigatórias da escola, sem perda nenhuma. Assim, seriam abordados conhecimentos, respeito e empatia com a diversidade/diferença, flexibilizando a estrutura curricular com a finalidade de promover uma cultura plural e democrática no Brasil. Mas, com essas práticas, os alunos serão outros, empáticos e respeitosos, o uso do nome social e do banheiro seria algo que viria naturalmente como obrigatório (a escola não pode ser TÃO contraditória assim). E digo mais, muitas escolas têm o uso do banheiro e nome social liberados, mas por falta de respeito das outras pessoas, a população TTT se rende ao não uso por medo de violências, chacotas, humilhações (E6 Transgênero Masculino, 21 anos).

Nas escolas onde estudei não tinham pessoas transgênero "assumidas". Acho que isso tem muito a dizer né?!. A escola como sendo o nosso segundo local de socialização, precisa sim ser mais inclusiva, principalmente com pessoas TTT. (...) se formos parar pra pensar, não é nem "evasão escolar". Ao meu ver essas pessoas são expulsas das escolas. 
Acredito que as escolas devem abraçar campanhas com palestras sobre diversidade e trazer desde sempre essas diferenças, empregando pessoas trans. Enfim, normalizando nossas vivências (E7 Transexual Feminina, sem identificação de idade).

Não! O respeito é primordial. Isso não tinha na época. Eu era a única trans. Se os professores, ao verem os insultos, tentarem ajudar aquelas trans e os banheiros serem abertos normalmente para nós sem ninguém negar nossa entrada para não passarmos mais constrangimento (E8 Transexual Feminina, 42 anos).

Nossos (as) entrevistados (as), em sua maioria, relataram-nos sobre a incompetência, violência e autoritarismo da escola em não reconhecer a diversidade/diferença na comunidade escolar. E quando perguntamos sobre "como" ou "o quê" a escola poderia fazer para se tornar um ambiente mais acolhedor para as TTTs, uma das soluções apresentadas, foi abordar e problematizar os temas de corpo, gênero e diversidade sexual envolvendo toda a comunidade escolar (equipe gestora, docentes, outros profissionais da escola, alunos e pais), uma vez que as TTTs sofrem com a transfobia vinda dessa comunidade.

Em relação ao uso do nome social, devemos levar em consideração que o direito à utilização do nome social na educação básica conquistado em 12 de setembro de 2017, no Parecer CNE/CP n 14, e em 19 de janeiro de 2018, na Resolução $\mathrm{CNE} / \mathrm{CP} \mathrm{n}^{\circ} 1 \mathrm{em}$ que ficou definido o respeito e o direito ao uso do nome social de travestis e transexuais nos registros escolares (Brasil, 2017). Sobre o direito ao uso dos sanitários referentes à sua identidade de gênero, de acordo com a Resolução $n^{\circ}$ 12/2015 do Conselho Nacional de Combate à Discriminação e Promoção dos Direitos de Lésbicas, Gays, Bissexuais, Travestis e Transexuais (CNCD/LGBT), estudantes transgênero poderão escolher qual sanitário usar e o tipo de uniforme escolar, de acordo com sua identidade de gênero (CNCD/LGBT, 2015). Entretanto, esses direitos conquistados são burlados e desrespeitados porque a inteligibilidade cisheteronormativa permanece ainda como hegemônica.

Os (as) entrevistados (as) também dizem da problematização com toda a escola em si. Eles citam o uso do tema como assunto transversal que deveria ser abordado em todas os componentes curriculares. Assim como também, deveria existir a realização de campanhas abordando o respeito à diversidade/diferença.

Acredito que esses "incidentes" possam ser tomados como dispositivos para dialogar e problematizar sobre as diferenças e promover uma aproximação das pessoas com temáticas e modos de existência distantes dos seus universos particulares. Penso que o diálogo sobre as expressões das diferenças seja uma das atribuições da escola, e assim possa contribuir com uma formação voltada para a cidadania e a paz (Peres, 2009, p. 253).

Em seguida, foram realizadas perguntas que motivassem nossos (as) participantes a relatarem suas vivências escolares sobre as principais formas de discriminação que eles enfrentaram em relação à sua identidade de gênero. Obtivemos as seguintes respostas:

Piadas sobre a aparência, uso do pronome errado etc. (E1 Transexual Feminina, 19 anos).

Foram várias (E2 Transexual Feminina, sem identificação de idade).

A falta de entendimento das pessoas sobre nós (E3 Transexual Masculino, sem identificação de idade).

Erro de pronome de tratamento, pessoas encarando, silêncio ensurdecedor [com a presença das TTTs] sendo que antes todos estavam conversando, olhares tortos (E4 Transexual Feminina, sem identificação de idade).

Agressão policial, nome social desrespeitado, identidade questionada sempre que possível (E5 Transgênero Masculino, 20 anos).

Já fui impedido de usar o banheiro no qual faço parte. Fui proibido de usar meu nome na chamada da escola. Já fui apontado por ser "aquela sapatão" que só fala mimimi. Perseguição da psicóloga da escola (pode ser até bizarro, mas eu chegava a me recusar a ir à sala dela, pois eu sabia que só transfobia ia sair dali); e para além da escola, términos 
de relacionamentos pelo fato de ser trans e a pessoa não conseguir, sentir vergonha disso; e por um tempo, tive que sair de casa pelo bem de minha saúde mental (E6 Transgênero Masculino, 21 anos).

$\mathrm{Na}$ época, as discriminações em relação a minha identidade de gênero vinham como "homofobia" e em sua grande maioria eram xingamentos, insinuações, vaias e olhares tortos nos corredores (E7 Transexual Feminina, sem identificação de idade).

Quando me bateram na escola, na saída, sem motivo, eu perdi um ano letivo pois não queria mais ir, E quando o professor disse que eu não era mulher, pra tá daquele jeito. Outra foi no banheiro. Obrigada a entrar no banheiro masculino. Foi horrível, humilhante, os meninos mostrando suas partes (genitais), dizendo que eu tava ali pra ver eles nus (E8 Transexual Feminina, 42 anos).

Concluindo, foi feita uma indagação se nos dias atuais, apesar de todas as desigualdades que perpassam a sociedade, se as TTTs se sentiam confiantes e inspiradas a perseguir seus sonhos. Tivemos as seguintes respostas:

Sim (E1 Transexual Feminina, 19 anos).

Sim, pois somos insistentes e existente perseverante. Somos resistência (E2 Transexual Feminina, sem identificação de idade).

Sim (E3 Transexual Masculino, sem identificação de idade).

Às vezes (E4 Transexual Feminina, sem identificação de idade).

Não (E5 Transgênero Masculino, 20 anos).

Sim! Sei que as lutas não param. É algo diário que temos que enfrentar, desde que acordamos (pelo menos no meu caso, em casa) até a hora de dormirmos. O medo também abala muito, mas se render ao medo me derrubaria (E6 Transgênero Masculino, 21 anos).

Inspirada nem tanto, já que pra dar o pontapé inicial eu preciso de um trabalho e como bem sabemos a quantidade de pessoas trans desempregadas é bem grande. Mas, sigo tentando e tendo as minhas [outras transexuais] como inspiração (E7 Transexual Feminina, sem identificação de idade).

Eu não acho que posso sonhar. Não tenho idade pra isso. Queria ter feito faculdade de letras ou turismo, mas como eu era trans da família, tudo era comigo. Se alguém ficava doente ou hospitalizada, eu que tinha que ir, pois, não trabalhava. Só estudava. Mas tô feliz, hoje mudei de nome. Sou E8 Transsexual Feminina que venceu muitas coisas, mas perdi sonhos (E8 Transexual Feminina, 42 anos).

Como é afirmado por Peres (2009), o gênero, assim como o corpo e a sexualidade, são construções sociais e históricas diretamente marcadas pela cultura e as relações de saber-poder que estabelecemos durante nossas vidas. Assim sendo, não estão determinados e podem adquirir novos contornos. Nesse sentido, o binarismo existente e o processo de normatização pelo qual as travestis, transexuais e transgêneros passam é explicitamente violento e cruel à medida que tenta a todo custo tornar a existência dessas pessoas ilegítima no reforço da exclusividade da categorização dicotômica.

Para tentar entender o quanto essas questões influenciam em seus desenvolvimentos pessoais, tanto no meio escolar como no cotidiano das TTTs, questionamos as/os entrevistadas/entrevistados sobre as formas de discriminação que vivenciaram devido à sua identidade de gênero. A maioria das respostas, está focada na ausência do uso do pronome de tratamento para se referir a essas pessoas, desrespeitos, olhares depreciativos e violência física também foram citadas, isto é, prevalece a transfobia nas vivências escolares e no cotidiano dessas pessoas (Miranda \& Oliveira, 2016).

Referente a essa indagação, a E8, de 42 anos, relata-nos que, na escola, sofreu violência física por parte dos colegas e foi desrespeitada por um professor devido à sua caracterização em harmonia com sua identidade de gênero. Ela também foi 
obrigada a entrar no banheiro masculino onde os garotos ficaram mostrando suas genitálias alegando que E8 devia vê-los nus. Essas razões a fizeram perder o ano letivo, pois não queria mais ir à instituição escolar.

Vale destacar ainda a resposta do Entrevistado E6, estudante de psicologia que se identifica como transgênero desde a adolescência, em que nos relatou, como anteriormente citado:

Já fui impedido de usar o banheiro no qual faço parte; fui proibido de usar meu nome na chamada da escola; já fui apontado por ser "aquela sapatão" que só fala mimimi; perseguição da psicóloga da escola (pode ser até bizarro, mas eu chegava a me recusar a ir a sala dela, pois eu sabia que só transfobia ia sair dali); e para além da escola, términos de relacionamentos pelo fato de ser trans e a pessoa não conseguir e sentir vergonha disso; e por um tempo tive que sair de casa pelo bem de minha saúde mental (E6 Transgênero Masculino, 21 anos).

As experiências vividas pela transexual e o transgênero citadas acima, mostram-nos o quanto o ambiente escolar pode ser hostil. E os profissionais que deveriam ser capacitados e instruídos a promoverem o respeito à diversidade/diferença, ao contrário, reproduzem as discriminações e a transfobia que as TTTs vivenciaram e ou vivenciam tanto na escola como em outros lugares.

Nesse contexto, concordamos com Peres (2009) quando afirma que essa postura de não flexibilização diante da expressão das diferenças só evidencia o fato de ainda estarmos presos a padrões fixos de corpo, de sexualidade e de identidade de gênero que não condizem com a realidade em que vivemos.

Mesmo diante desse contexto avassalador e excludente, em sua maioria, as TTTs ainda possuem e se sentem confiantes e inspiradas a perseguirem os seus sonhos.

Sobre essa questão, o E6 transgênero masculino e estudante de psicologia, explicita que: "sim, sei que as lutas não param, é algo diário que temos que enfrentar, desde que acordamos (pelo menos no meu caso, em casa), até a hora de dormirmos. O medo também abala muito, mas se render ao medo me derrubaria".

E7, transexual feminina, com ensino médio completo e desempregada, revela-nos que não se sente tão motivada e aponta o desemprego como principal causa desse desânimo. Para ela, seria o "pontapé" inicial. Mas, tem dificuldade em razão dos preconceitos enfrentados por ser pessoas trans no mercado de trabalho, contudo, continua tentando e lutando.

Ainda, vale ressaltar a resposta de E8, transexual feminina de 42 anos, com ensino médio completo e doméstica. Ela nos relata que tinha o sonho de fazer faculdade, mas nunca teve oportunidade: "eu não acho que posso sonhar. Não tenho idade para isso". Todavia, ela diz que se sente feliz de ter conseguido mudar seu nome e por ter vencido tantas coisas, apesar de ter perdido seus sonhos. Podemos intuir que antigamente, a pressão, violência social e o silenciamento eram ainda piores do que as pessoas trans mais jovens enfrentam, pois, tanto a mídia como a escola, de alguma maneira, têm abordado a equidade de gênero e o respeito à diversidade/diferença mesmo que essa abordagem ainda seja muito tímida (Miranda \& Oliveira, 2016).

Nos depoimentos citados acima, pode-se perceber o grau de preconceito e exclusão relatados em vários momentos pelas TTTs. Essa transfobia exerce um impacto negativo na construção enquanto pessoa de direito e de cidadania, afetando a sua busca por emprego e até de uma formação inicial e continuada. Entretanto, os resultados gerais, apontam que mesmo expostas a um processo tão cruel de transfobia na sociedade e na escola, as pessoas trans continuam se sentindo inspiradas a irem atrás de seus desejos e de seus sonhos. As TTTs possuem uma postura de resistência frente a essas situações e precisam sim de políticas que as assistam em suas especificidades, como nos indica Peres (2009).

\section{Considerações Finais}

Em nossas análises, pudemos observar a existência de alguns elementos que propiciam a evasão/expulsão escolar das TTTs. É evidente nas respostas de alguns participantes, da pesquisa, que a escola e a família são representações de ambientes 
de repressão e violências. Alguns relatos apontam essas vivências como sendo o palco de processos dolorosos, pois, muitas vezes o desprezo, humilhação e transfobia fizeram parte do cotidiano escolar deles(as). Esses fatores acabaram corroborando para que acontecesse a evasão, ou melhor dito, a expulsão das TTTs no âmbito escolar e da sua participação como cidadãs em nossa sociedade.

Existe grande necessidade de estudar mais a temática da transfobia na escola e, a partir desses estudos denunciar e desestabilizar a transfobia. Nesse caminho, em relação às pesquisas realizadas, observa-se que as ações que restringem a liberdade das TTTs, são variadas, desde ações simples como foi evidenciado por permitir que vistam roupas que identificam com seu gênero, expondo suas opiniões através delas, ir aos banheiros que se reconhecem até ações que exigem uma transformação crítica das políticas sociais, reconhecimento e respeitando o nome social. Assim, mesmo existindo esse neoconservadorismo, essa exclusão e, consequentemente, a (re)produção da transfobia na escola, felizmente esse cenário vem se modificando. Todas as atitudes que buscam integrar as TTTs em todos os aspectos sociais comuns aos indivíduos, como por exemplo a liberação para utilizar o banheiro no qual se sente confortável de acordo com o seu gênero, podem contribuir para que o ambiente escolar seja menos hostil e opressor a esse grupo, amenizando a evasão/expulsão que ainda é realidade tão presente neste grupo.

Outras pesquisas a serem desenvolvidas, poderia focar nas estratégias utilizadas pelas TTTs e pelas escolas no combate à transfobia, como a promoção de ações (palestras e mesas redondas) com pessoas trans, travestis e transsexuais em escolas, no intuito de conscientizar e diminuir o preconceito e a violência que há muito tempo são reproduzidos por essas instituições de ensino e que acarretam danos às vezes irreversíveis nessas pessoas.

\section{Referências}

Alves-Mazzotti, A. (1999). O Método nas Ciências Sociais. In Alves-Mazzoti, A. J.; Gewandsznajder, F. O Método nas Ciências Naturais e Sociais: Pesquisa Quantitativa e Qualitativa (pp. 99-197). Pioneira.

Arán, M. (2006). A transexualidade e a gramática normativa do sistema sexo-gênero. In Ágora: Estudos em Teoria Psicanalítica, 9(1), 49-63.

Bardin, L. (1997). Análise de Conteúdo. Edições 70.

Bauer, M. W. (2010). Análise de Conteúdo clássica: uma revisão. In Bauer, M. W.; Gaskell, G. (Orgs.). Pesquisa Qualitativa com Texto, Som e Imagem: um manual prático (pp. 189-217). Vozes.

Benedetti, M. R. (1997). “Toda feita”: gênero e identidade no corpo travesti. In Reunión de Antropología del Mercosur, 2.

Bento, B. (2008). Na escola se aprende que a diferença faz a diferença. In Bento, B.. O que é transexualidade (pp. 163-176). Editora Brasiliense.

Bento, B. (2017). A Reinvenção do Corpo - Sexualidade e Gênero na Experiência Transexual. Salvador: Editora Devires.

Bento, B., \& Pelúcio, L. (2012). Despatologização do gênero: a politização das identidades abjetas. Revista Estudos Feministas, 20 (2), 559-568.

Biancarelli, A. (2010). A Diversidade revelada. São Paulo: Centro de Referência da Diversidade: Ambulatório de Saúde Integral para Travestis e Transexuais.

Brasil (2017). Ministério da Educação. Conselho Nacional de Educação. Parecer CNE/CP n. 14/2017, aprovado em 12 de setembro de 2017 - Normatização nacional do uso do nome social na educação básica. Brasília, DF: MEC/CNE. http://portal.mec.gov.br/index.php?option=com_docma n\&view=download\&alias=72921-pcp014-17-p df\&category_slug=setembro-2017-pdf\&Itemid=30192.

Butler, J. (2003). Problemas de gêneros: feminismo e subversão da identidade. Civilização Brasileira.

Butler, J. (2017). A vida psíquica do poder: teorias da sujeição. Autêntica.

Cardoso, R. L. et al. (2005) Pesquisa científica em contabilidade entre 1990 e 2003. RAE-revista de administração de empresas, 45(2), 34-45.

Chidiac, M. T. V., \& Oltramari, L. C. (2004). Ser e estar drag queen: um estudo sobre a configuração da identidade queer. In Estudos de Psicologia, 9 (3), 471-478.

Conselho Nacional de Combate a Discriminação e Promoções dos Direitos de Lésbicas, Gays, Travestis e Transexuais (CNCD/LGBT) (2015). Resolução ${ }^{\circ}$ 12 , de 16 de Janeiro de 2015. https://www.defensoria.sp.def.br/dpesp/Repositorio/39/Documentos/Resolucao\%2012\%202015\%20$\% 20$ Conselho $\% 20$ LGBT $\% 20$ da $\% 20$ Secretaria $\% 20$ de $\% 20$ Direitos\%20Humanos\%20da\%20Presid\%C3\%AAncia\%20\%20-

$\% 20$ Nome $\% 20$ social $\% 20 \mathrm{e} \% 20$ uso $\% 20 \mathrm{de} \% 20$ banheiro $\% 20$ nas $\% 20$ escolas.pdf.

De Oliveira, M. M. (2007). Como fazer pesquisa qualitativa. Vozes. 
Research, Society and Development, v. 10, n. 10, e19101018336, 2021

(CC BY 4.0) | ISSN 2525-3409 | DOI: http://dx.doi.org/10.33448/rsd-v10i9.18336

Fonseca Júnior, W. C. da F, \& Wilson, C. (2005). Análise de Conteúdo: métodos e técnicas de pesquisa em comunicação. Atlas.

Foucault, M (2007). História da sexualidade. Volume 1: A vontade de saber. Graal.

Francisco, T. J., Mendes, S. A. F., \& Meira, A. C. G. A. de. (2019). Gender, sexuality and diversity at a school: results of a research project developed at Ifnmg, Campus Salinas. Research, Society and Development, 8(9), 01-11. DOI: https://doi.org/10.33448/rsd-v8i9.1323

Freire, P (2011). Pedagogia do oprimido. Paz e Terra.

Gomes, R (2016). Análise e Interpretação de dados de Pesquisa Qualitativa. Minayo, M. C. de S. (Org.). Pesquisa Social: teoria, método e criatividade. Vozes.

Hutcheon, L (1985). Uma teoria da paródia. Edições 70.

Jayme, J. G. (2002). Travestis, transformistas, drag-queens, transexuais: pensando a construção de gêneros e identidades na sociedade contemporânea. Congresso Brasileiro de Ciências da Comunicação, 5, Salvador.

Kulick, D (2008). Travestis: prostituição, sexo, gênero e cultura no Brasil. Fiocruz.

Lessa, P., \& Oliveira, M. (2013). A invisibilidade dos transexuais na educação: análise dos discursos legais sobre o nome social nas escolas do Brasil. Caderno de Gênero e Tecnologia.

Ludke, Menga, \& André, Marli (1986) Pesquisa em educação: abordagens qualitativas. Em aberto, 5, 31.

Miranda, M. H. G. de, \& Oliveira, S. M. D. de (2012). Teoria social e epistemologia feminista: desestabilizações das categorias sexo, gênero e sexualidade. Estudos de Sociologia, 1, 18.

Miranda, M. H. Gonçalves de, \& Oliveira, A. C. Amorim (2016). Os Limites das Categorias Heteronormativas no cotidiano escolar e a Pedagogia Queer: o caso do uso do banheiro. Revista Educação e Cultura Contemporânea, 13(32), 350-373.

Peres, W. S. (2009). Cenas de exclusões anunciadas: travestis, transexuais, transgêneros e a escola brasileira. Diversidade sexual na educação: problematizações sobre a homofobia nas escolas. Brasília: Ministério da Educação, Secretaria de Educação Continuada, Alfabetização e Diversidade, 235264.

Peres, W. S., \& Toledo, L. G. (2011). Dissidências existenciais de gênero: resistências e enfrentamentos ao biopoder. Revista Electrónica de Psicología Política, 261-277.

Podestá, L. L. de (2019). Ensaio sobre o conceito de transfobia. Revista Periódicus, 1(11), 363-380.

Saffioti, H. (1997). Violência de gênero: o lugar da práxis na construção da subjetividade. Lutas sociais, (2), 59-79.

Santos, D. B. C. dos, \& Araujo, D. C. (2009). Sexualidades e gêneros: questões introdutórias. In Anais do Congresso Fazendo Gênero (pp. 25-28).

Silva, D. S. N., Miranda, M. H. G. de, \& Santos, M. C. G. (2020). Homofobia e interseccionalidade: sentidos condensados a partir de uma pesquisa bibliográfica. Revista Interritórios, 5(1), 200-224.

Vieira, V. A. (2002). As tipologias, variações e características da pesquisa de marketing. Revista da FAE, 5(1). 